\title{
Investigation on the physical properties and diffusion layer phase transformation at the interface of Sialon-Duplex Stainless-Steel bonding
}

\author{
Mohamed Ahmed Rady', Patthi Hussain 1, Nagoor Basha Shaik ${ }^{1}$ and Balaji Bakthavatchalam ${ }^{1}$ \\ ${ }^{1}$ Mechanical Engineering Department, Universiti Teknologi PETRONAS, 32610 Seri Iskandar, Perak, Malaysia \\ Phone: +60194704616
}

ABSTRACT - Joining SiALON to duplex stainless steel utilizes the properties of two materials which may provide an opportunity for distinctive applications. Ceramic is hard and operates at a high temperature but it is brittle whereas metal is tough but it can work at a low temperature. The benefits of the best properties of both materials can be utilized by joining them. The objectives of the research work are to investigate the physical properties and the phase transformation at the interface and at the inter-diffusion layer in between the SiAION and duplex stainless steel. The experiment incorporated nitriding, then diffusion bonding the duplex stainless steel using the hot press. Bonding was carried out at $1200^{\circ} \mathrm{C}$ for the holding times of 30 minutes and 1 hour. Metallography and micro analyses were conducted to achieve the above objectives. The study has demonstrated that 30 minutes joining time is sufficient to develop the thickness of the interface. However, 1 hour joining duration achieved cohesive and sound diffusion bonding of the SiAION to duplex stainless steel. This is possible due to the formation of diffusion interlayer which accommodates the residual stress presence during cooling down process.

ARTICLE HISTORY

Received: $24^{\text {th }}$ July 2020

Revised: $19^{\text {th }}$ Jan 2021

Accepted: $27^{\text {th }}$ May 2021

\section{KEYWORDS}

Bonding;

interfaces;

residual stresses;

sialons;

steel.

\section{INTRODUCTION}

Amid various developments in material science and engineering, ceramic applications are often much smaller than the ideal hypothesis predicts. SiAlON is a prominent high temperature resistant ceramic material whose properties are similar to silicon nitride $\left(\mathrm{Si}_{3} \mathrm{~N}_{4}\right)$ ceramics that are exceptionally strong. Sialon, a silicon aluminium silica oxynitride family, has the same silicon nitride characteristics and is much simpler to manufacture and shape into complex forms. Sialons provide improved durability even under extreme conditions like elevated temperature, fracture toughness, high corrosion and mechanical strength. The fusion of alumina, Silicon nitride, silica and aluminium nitride leads to the production of SiAlON, and they are mainly employed in the fabrication of engines, turbine parts, cutting tools and bearings. Since Sialon ceramics have a fragile character, machining holes and adhesive bondings should be avoided as they cannot withstand temperature beyond $100{ }^{\circ} \mathrm{C}$. Therefore, ceramics' joining to metals is necessary for hightemperature applications, especially in the heat engine [1,2]. Ceramic is challenging, but it operates at a low temperature. On the contrary, metals work at high temperatures, but they undergo multiple stress sites and harmful effects. With fascinating properties such as high mechanical strength, corrosion resistance, and weldability, duplex stainless steels that retain their microstructure even after $1600{ }^{\circ} \mathrm{C}$ can be considered the right solution when combined with Sialon ceramics. This steel can be viewed as a combination of ferritic and austenitic phases, which are widely exploited in heat exchangers, nuclear plants, vessels, and chemical equipment [3]. For certain instances, the new duplex stainless steels with a very high content of $\mathrm{Cr}$, Mo and $\mathrm{N}$ have a better tolerance to corrosion than type 2205 plates of steel and are also competitive with 6-Mo steels. Though both materials have useful properties that can be utilized, the joining process of both is problematic due to the temperature difference. Several workers joined the ceramics to metals using brazing $[4,5]$ with promising results [6]. However, this method is not suitable for high-temperature application due to the brazing materials' lower melting temperature. Figure 1 displays the schematic arrangement for brazing and diffusion bonding joints. In contrast with more commonly accepted surface treatment methods, the nitriding method invloves compartively low temperature. Due to its ability to serve many applications, nitriding process is considered to be the most accepted technique for hardening of steels. Nitriding is creatively employed by engineers and metallurgists to make the process viable and commercially acceptable. When we are conscious of the benefits of this method, the usage and use of nitriding will begin to expand.

The process of applying pressure to form a joint between similar or dissimilar metals where the bonding pressure and applied heat stimulates atoms to be diffused on the interface is known as diffusion bonding. Diffusion bonding applies to various metals, alloys, and nonmetals that can be joined in a diverse gamut of combinations or compositions. One can readily control the bonding operation's progress by varying the temperature of heating, the bonding pressure, the Vacuum in the process chamber, the holding time (duration of pressure) using various surface preparation forms, etc. If one is to operate under optimal conditions, one should have a clear idea about the relationships between the above variables. Atoms on the weld interface diffuse with each other in solid and for liquid a molten interlayer is required for diffusion during this process. Joints made by diffusion bonding meet the most critical structure requirements in terms of strength, 
toughness, tightness, and resistance to heat and corrosion. The main advantage of diffusion bonding joint is that impurity is significantly less as the process is done under a vacuum. The work done on the diffusion bonding of austenitic stainless steel to SiAlON showed the formation of cracks adjacent to the interface layer [7]. Ren et al. [8] investigated the diffusion bonding process's effect on duplex stainless steel using a thermomechanical simulator. The authors reported a higher joint shear strength of $418 \mathrm{MPa}$, indicating the development of complicate structures. Zeng et al. [9] examined the performance of diffusion bonded joint in $\mathrm{Zr} 705$ alloy joints at a maximum temperature of $960{ }^{\circ} \mathrm{C}$ where authors obtained a maximum efficiency of $104.8 \%$. Lin et al. [10] studied the behaviour of elements during the diffusion bonding of a Copper/Nickel sample. Due to the migration of grain boundaries and grain coalescence, abnormal grains were observed on the interlayer of the sample. In a different study, Li et al. [11] conducted diffusion bonding at an ultralow temperature of $100{ }^{\circ} \mathrm{C}$ which showed a maximum shear strength of $112.9 \%$ higher than conventional diffusion bonded joints. Recently, Ji et al. [12] proposed a novel friction stir diffusion bonding to avoid hooks during the joining of thin sheets. They obtained excellent joints at the interface without any hooks.

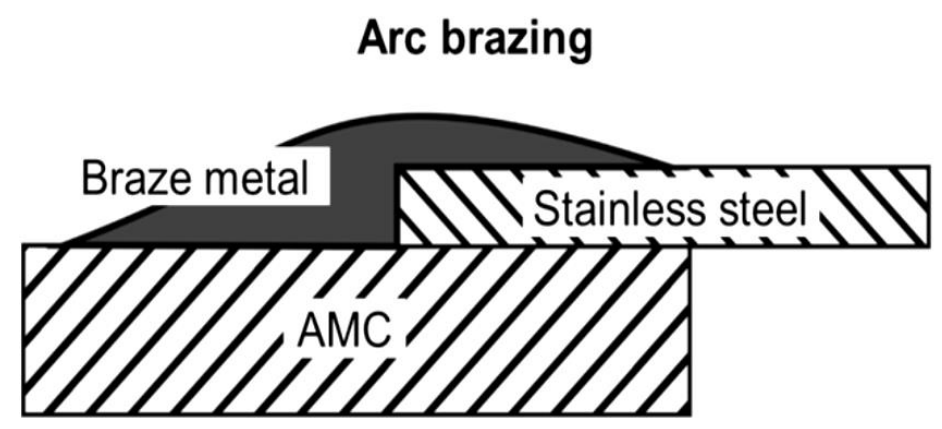

\section{Diffusion bonding}

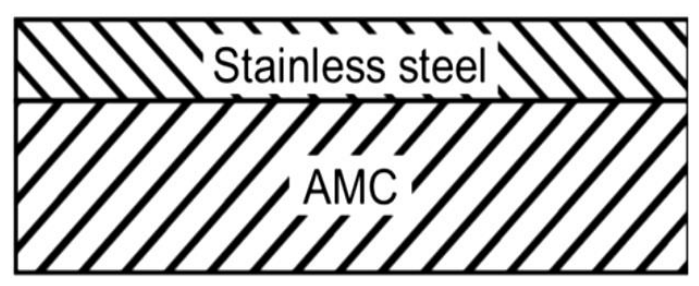

Figure 1. Schematics of joining in brazing and diffusion bonding [13]

Velmurugan et al. [14] joined duplex stainless steel with Ti-6Al-4V alloy at a lower temperature using diffusion bonding technique. Authors observed that increase in temperature led to the improvement of the diffusion coefficient. Kundu et al. [15] experimentally investigated the bond strength of diffusion bonded titanium and duplex stainless steel with temperature ranging from 800 to $950{ }^{\circ} \mathrm{C}$. They found an increase in the bonded material's width due to the temperature rise accompanied by bond strength decrease. However, ferritic joining to stainless steel was quite successful in forming the intermediate layer that absorbed the residual layer raised at the interface [16, 17]. The diffusion joining of stainless steels and SiAlONs has excellent potential to be utilized for engineering applications. The joining setup for conducting the diffusion welding process is depicted in Figure 2.
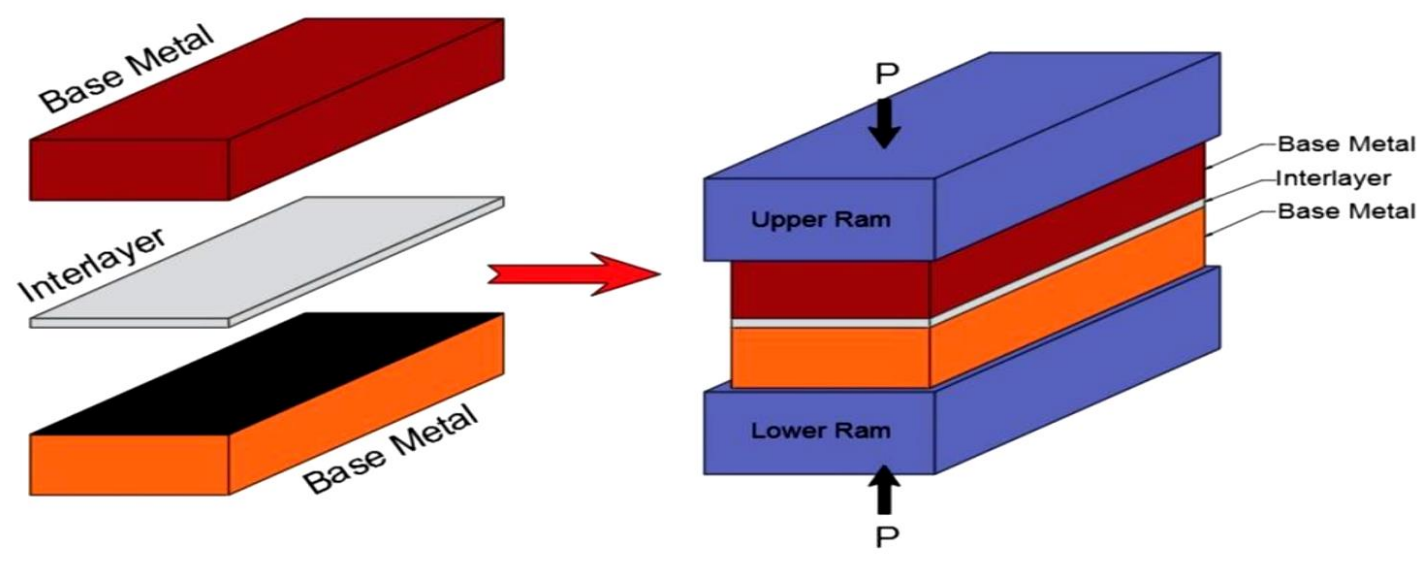

Figure 2. Joining setup for conducting diffusion welding [18]

Duplex stainless steel and SiAlON were bonded in this analysis, and their properties and phase transitions were investigated at the interface layer. This is particularly important as the future application of joining duplex stainless steel to SiAlON might utilize the exceptional properties that existed in both materials. Although SiAlON possesses excellent mechanical and physical properties such as high-temperature capability without creeping, great oxidation resistance and good wear resistance, it cannot be used alone for the reason of its brittleness [19]. In contrast, duplex stainless steels have high durability, but they work at low temperature compared to SiAlON. Joining ceramic with steel is critical because of the vast number of applications that can be utilized in [20]. Other than that, the capacity of joining the SiAlON to duplex stainless steel might use the exceptional properties that existed in both materials. The issue of joining SiAlON and nitrided duplex stainless steel happens during the cooling stage due to their differences in thermal expansions, which leads to high residual stress adjacent to the joint. This stress causes plastic deformation and breaking. The positive characteristics of 
SiAlON ceramic may be combined with a promising alternative like metals in chosen areas, typically stainless steel. Many studies [21-24] reported that conventional fusion welding was ineffective in joining ceramics and metals because of their inconsistent melting point and residual stress. On the other hand, diffusion bonding is one of the most feasible forms for efficient bonding ceramics with steels. This work's main objective is to investigate the physical properties of the diffusion bonding of SiAlON to nitrided duplex stainless steel at two diverse diffusion bonding time, which are 30 minutes and 1 hour. The phase transformations at the interface were also investigated.

\section{METHODS AND MATERIALS}

\section{Materials}

In this study, $201 \beta$-SiAlON procured from Universal SiAlONs (Newcastle) Ltd. UK with measurements of $20 \mathrm{~mm}$ distance across and $4 \mathrm{~mm}$ thickness was chosen due to their high temperature and high stress-resistant properties. The above mentioned SiAlON was joined with a 2205 duplex stainless steel obtained from E Steel Sdn Bhd. The gap of 20 $\mathrm{mm}$, around the pole of duplex stainless steel was reduced to $1.5 \mathrm{~mm}$ using electrical discharge machining (EDM). The coin-like duplex steel was ground and polished to a mirror finish on both sides. Meanwhile, before starting the diffusion bonding process, the steel sample was rinsed with acetone.

\section{Nitriding}

The process of diffusing nitrogen on the metal surface to create a case hardened surface is known as nitriding [25], [26]. Parameters such as furnace temperature, process control, gas flow, time, process chamber maintenance must be given utmost care to perform a proper nitriding process. Consideration of these parameters aids in the reduction of distortion along with residual stresses. The Duplex stainless steel was cleaned using ethanol and nitriding treatment through quartz model OTF-1200X-3CLV. The method temperature set through the temperature controller was $1200^{\circ} \mathrm{C}$ for 8 hours. In this process, nitriding was performed on duplex stainless steel so that the decomposition of nitrogen in the SiAlON could be suppressed from diffusing into the steel. The furnace samples were purged by nitrogen before the heat was applied for 15 minutes. After that, nitrogen gas was used for the respective times. Figure 3 illustrates the experimental setup of a normal nitriding process.

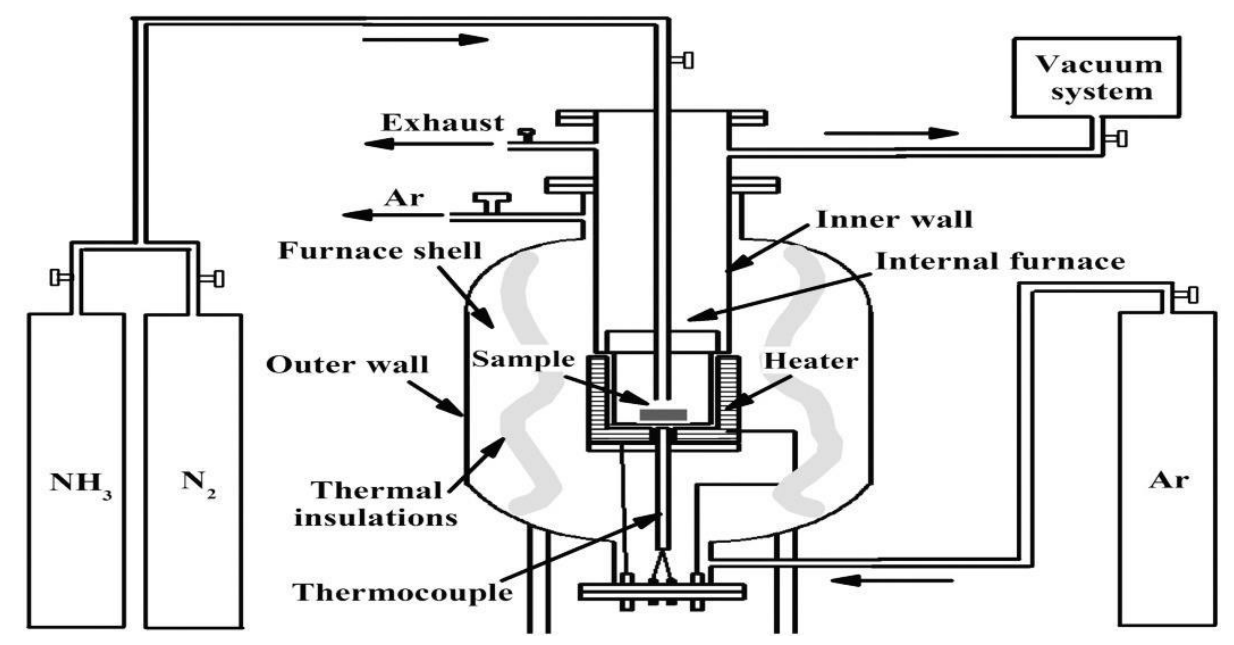

Figure 3. Experimental setup of the nitriding process [27]

In contrast with more commonly accepted surface treatment methods, the nitriding method involves comparatively low temperature. Due to its ability to serve many applications, the nitriding process is considered the most accepted technique for hardening steels. Engineers and metallurgists creatively employ nitriding to make the process viable and commercially acceptable. When we are conscious of this method's benefits, the usage and use of nitriding will expand.

\section{Surface Preparation}

The proposed sample was cut and machined into $20 \mathrm{~mm} \times 20 \mathrm{~mm} \times 4 \mathrm{~mm}$. Using SiC emery paper, the sample surface was polished. The samples were etched with nitric acid (for 45 seconds) and dried in hot air until the diffusion was done. Chemical treatment of the mating surfaces stabilizes the strength of the bond, but different agents act differently. Furthermore, the prepared specimens were assembled into a sandwich-style arrangement before the welding. In a vacuum chamber of the diffusion bonding unit, the prepared samples were placed between the hydraulic ram. Meanwhile, Vacuum cleans the metal surfaces and causes oxide films to sublime with the result that the joint strength is enhanced and the materials' properties are improved. 


\section{Diffusion bonding}

In diffusion bonding, the mating surfaces are heated to temperatures above or below the recrystallization point under slight pressure. For this reason, metals and alloys can be joined without markedly affecting their physicomechanical properties. The joining of SiALON to nitrided duplex stainless-steel was arranged in which the nitrided duplex stainless steels was sandwiched in between the two-disc of SiAlON pieces. The diffusion bonding was conducted using the hot press machine, Nisshin Giken vacuum hot press furnace is shown in Figure 4. The inner wall of the graphite die was prevented from having contact with the samples to be joined. Boron nitride was utilized to maintain a strategic distance from the reaction with the samples. Joining was carried out by heating the materials to $1200{ }^{\circ} \mathrm{C}$ in a vacuum condition of $4.7 \times 10^{-1} \mathrm{MPa}$ at a heating rate of $5{ }^{\circ} \mathrm{C} / \mathrm{min}$. A uniaxial load of $16 \mathrm{MPa}$ was applied for a dwelling time of 30 minutes and 1 hour. After dwelling, the load was released gradually, and the sample was cooled down to $700^{\circ} \mathrm{C}$ at a cooling rate of $5^{\circ} \mathrm{C} / \mathrm{min}$. After that, the sample was held to cool down in the hot press to room temperature.

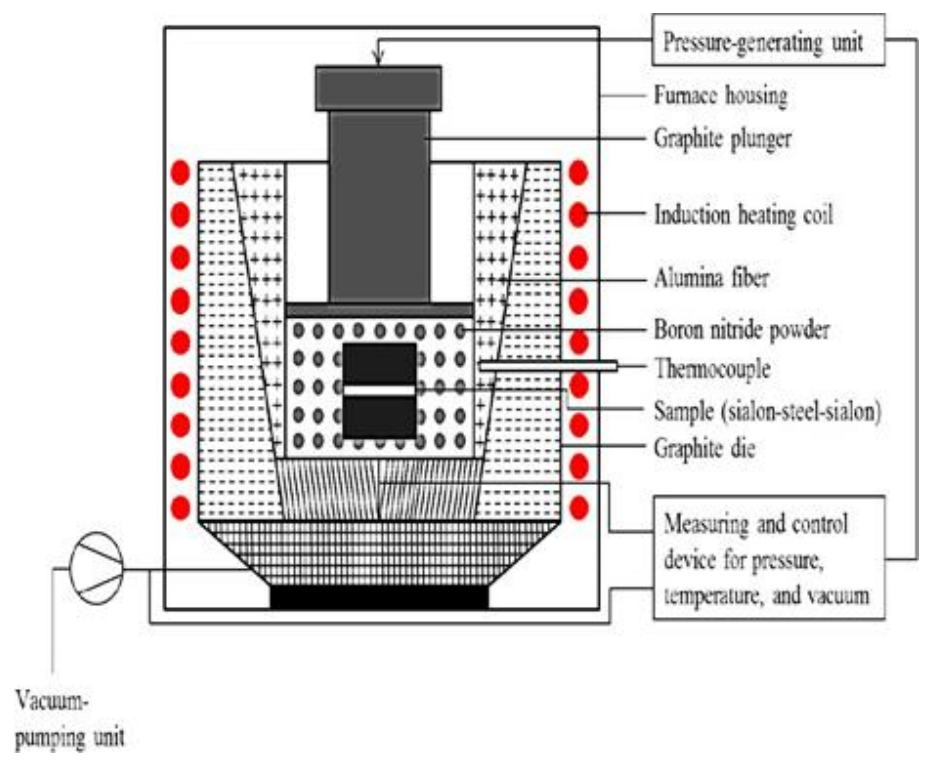

Figure 4. Schematic diagram of the diffusion bonding process

\section{Characterization}

Metallography analyses were conducted at the cross-section of the joint. A Diamond cut-off machine was used to cross-section the joint samples. Then the samples were ground and polished up to $1 \mu \mathrm{m}$ using abrasive papers and diamond paste, respectively. An optical microscope was employed to observe the microstructures of the transformation phases. Electron micrographic analyses and microanalyses were conducted using a scanning electron microscope (Zeiss Leo 1430) with Energy-dispersive X-ray spectroscopy (EDX). The SEM device has an electrostatic beam blanker that can result in a maximum resolution and acceleration voltage of $5 \mu \mathrm{m}$ and $30 \mathrm{kV}$. In general, SEM is useful in characterizing specimens up to a few nanometers or micrometres with images magnified from $\sim 10$ to more than 300000. SEM can also provide valuable information on chemistry, the alignment of crystals and the internal stress distribution, in addition to knowledge on surface topography.

\section{RESULTS AND DISCUSSION}

The choice of techniques for the analysis of diffusion-bonded joints is governed by the nature of the effects involved and state of the art. These techniques are frequently metallography, electron microscopy, spectral analysis, X-ray microanalysis, X-ray diffractometry, tracer analysis, microhardness measurement, and determination of mechanical properties at low and high temperatures, tests for long-term strength and creep, determination of thermal stability and corrosion resistance, etc. Whatever the technique used, it should be able to resolve localized features. For proper evaluation of the diffusion-bonded zone, several methods may be used at a time.

\section{Microstructure analysis}

Figure 5 shows the microstructure at a 1-hour bonding time. The figure shows the interface bonding cross-section joint between duplex stainless steel (DSS) and SiAlON. It indicates that sound bonding was achieved with no formation of gap and cracks. The formation of the diffusion layer is also depicted in Figure 6. The interface layer is cohesive, which shows that the interfusion and interaction have taken place. The phenomena were further investigated by SEM with EDX. Although diffusion bonding was achieved for the sample joining at 30 minutes, as shown in Figure 7, cracks were also formed at the joint's back side, as shown in Figure 8. This phenomenon could be due to less bonding time to create the diffusion layer to accommodate the residual stress at the interface compared to the sample above. The bonding layer for 
the 1-hour sample was slightly thicker than the 30 minutes sample, which is due to the longer dwelling time in the hot press $[28,29]$.

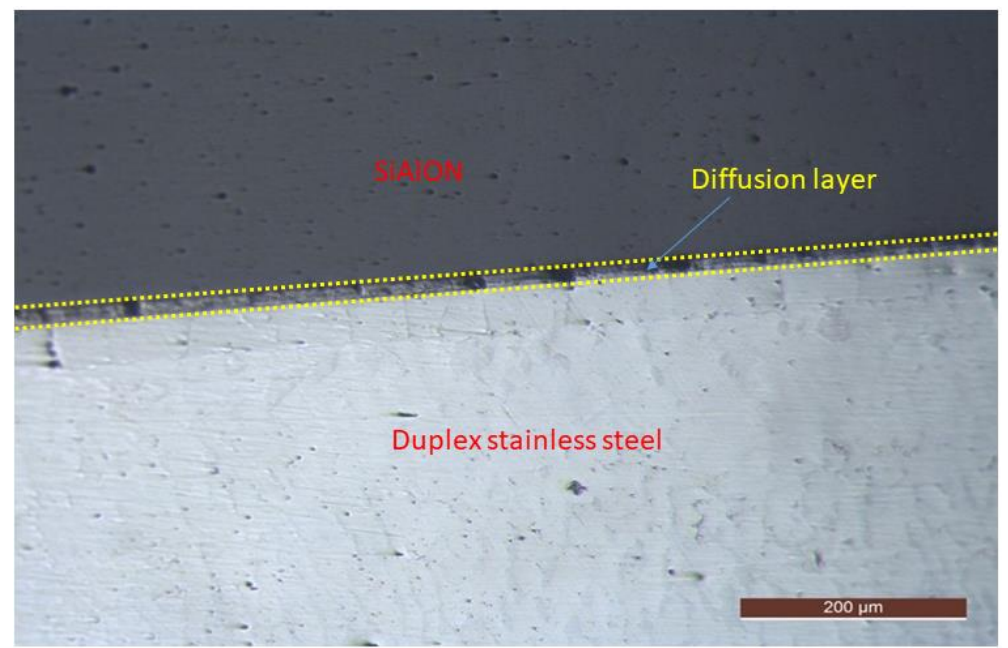

Figure 5. Optical micrograph of the 1-hour bonding time joint

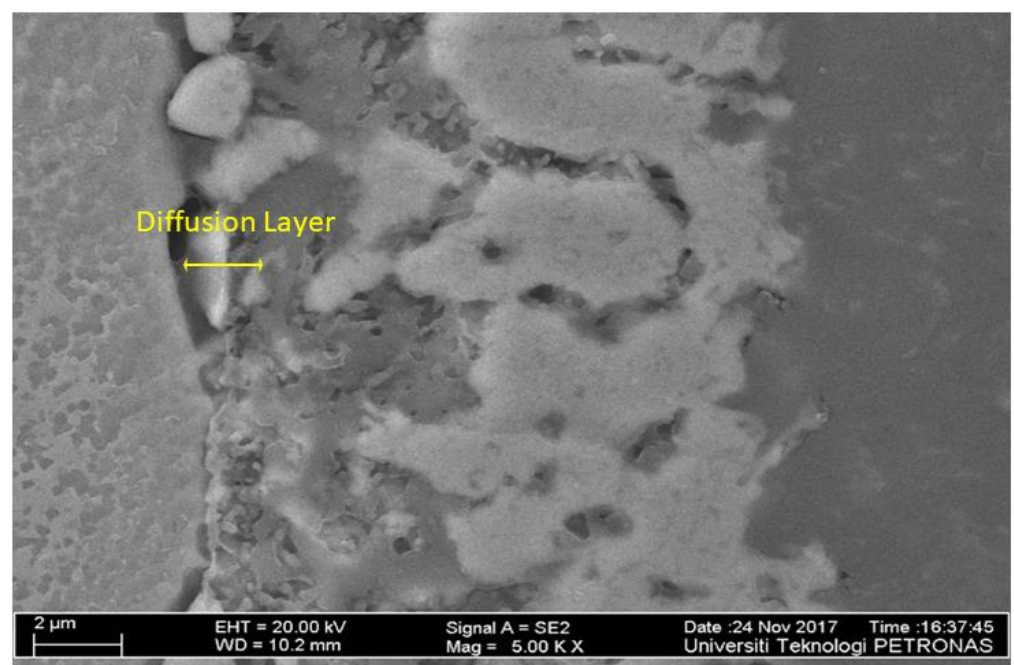

Figure 6. Scanning electron micrograph of the 1-hour bonding time joint

From the above image (Figure 6), it was clear that good bonding was formed at the interface of the bonded material accompanied by reaction and interdiffusion strains. The interparticle differences reduced as the temperature rises, which means that the bonded material's surface density is sensitive to the temperature described in the previous literature [30]. It can also be noted that two bonding interfaces, namely the SiaAlON interface and duplex stainless steel interface, confirm the success of diffusion bonding. Furthermore, compared with grains of duplex stainless steel, the sialon grains showed a smooth morphology due to the dissolution of sialon on the Sialon/Duplex stainless steel interface. On the other side, there was wavy deformation on the duplex stainless steel interface attributed to the high melting point of the studied duplex stainless steel. 


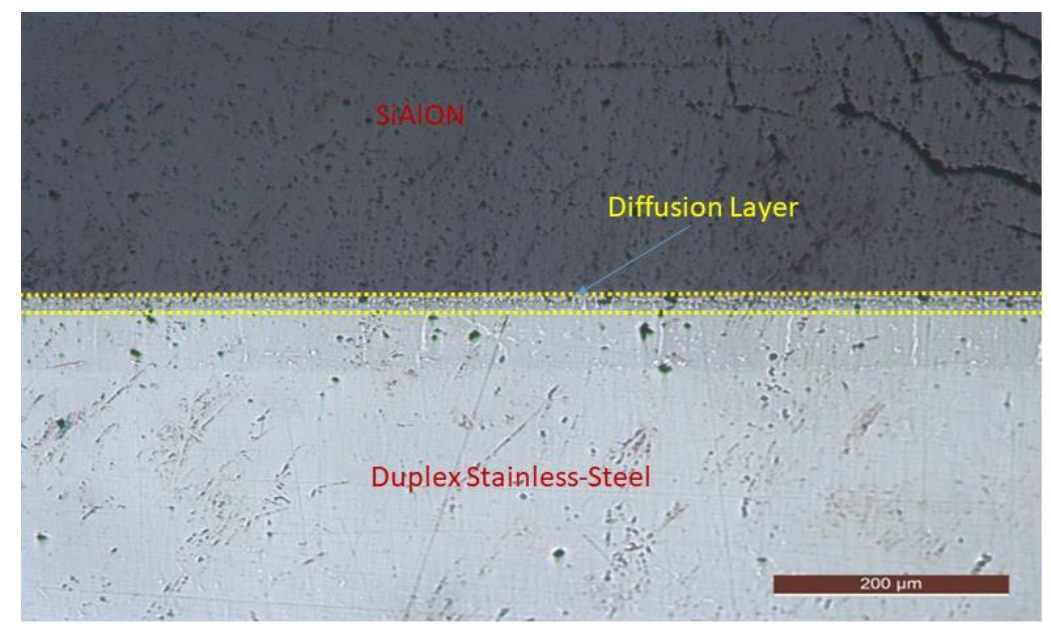

Figure 7. Optical micrograph of the 30 minutes bonding time joint

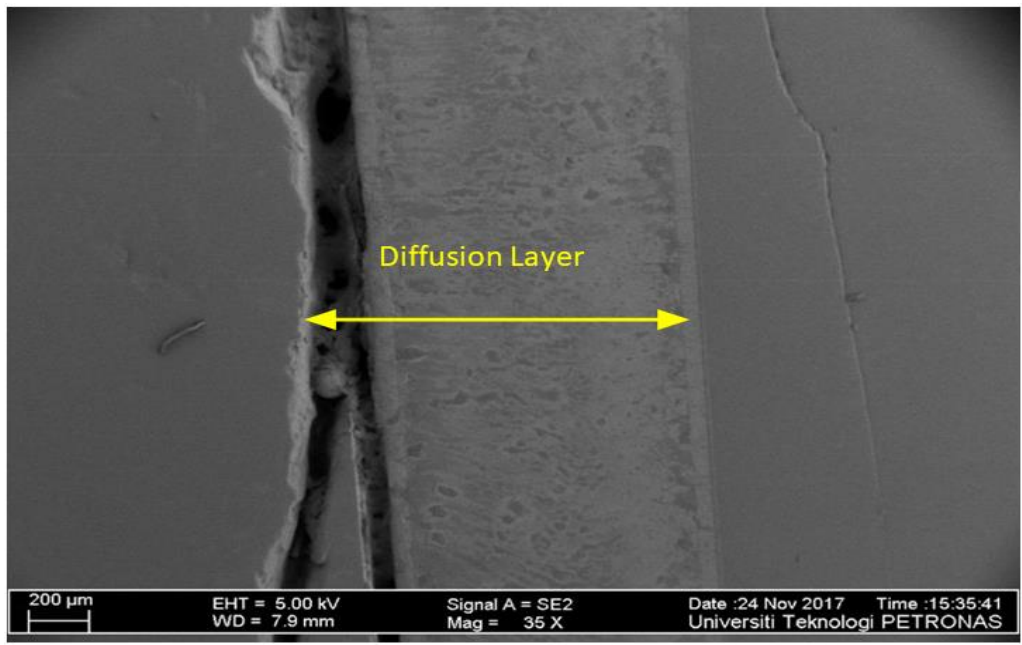

Figure 8. Scanning electron micrograph of the 30 minutes bonding time joint

Optical microscopy is an effective technique to analyze the distribution of grains and their size. Based on Figure 8, it was confirmed that the sample possesses equiaxed grains, which has a significant difference between the interior grain and adjacent grain, which followed the same trend of the previous report [31]. The interface's micrographs showed etched region, discontinuities, and microcracks contributed by the less bonding time of 30 minutes. Besides, the image demonstrates that the width of the bonded layer (diffusion zone) increased with an increase in temperature and more than than that, several other layers of the diffusion zone have not been resolved due to the limited features of optical micrographs.

\section{EDX Analysis}

In the present study, the concentration of elements across the joint was analyzed from duplex stainless steel to SiAlON. Figure 9 and 10 shows the concentration profile across the joints of 30 minutes and 1 hour, respectively. Analysis of the SiAlON exhibited that the dominant elements were silicon and nitrogen. Si and $\mathrm{N}$ were found at high concentration only at the interface layer, but this concentration percentage was less towards the steel. On the other hand, the dominant elements of steel, which are iron and chromium, decreased towards SiAlON. There were minor concentrations observed for other elements, which are $\mathrm{Al}, \mathrm{O}$ and $\mathrm{Y}$, compared to the concentration of the dominant elements of $\mathrm{Fe}, \mathrm{Cr}, \mathrm{Si}$, and $\mathrm{N}$, as can be seen in the figures. Besides, there were no other elements detected from SiAlON in the steel except Si and steel's elements. The concentration observed for $\mathrm{Si}$ in steel for 30 minutes, and 1-hour joinings are $0.42 \%$ and $0.45 \%$, respectively.

The EDX analysis across the joint's interface bonding shows that inter-diffusion between the duplex stainless steel and SiAlON has been carried out. The inter-diffusion for the sample joining at 30 minutes is shown in Figure 6. At the interface and diffusion layer, elemental compositions of both materials can be found. High concentration of Fe in the duplex stainless steel diffused into SiAlON. Similar phenomenon for the samples joints at 1 hour shows the inter-diffusion of both elements from duplex stainless steel and SiAlON, as shown in Figure 7. At the interface of sample joining at 30 minutes, the interfusion elements' presence was found to be 20 wt. $\% \mathrm{Fe}, 50$ wt.\% $\mathrm{Cr}, 10$ wt. $\% \mathrm{Si}$ and 5 wt. $\%$ Al. 
Meanwhile, for the sample for joining at 1 hour, the presence of the interface element was $20 \mathrm{wt} \% \mathrm{Fe}, 45 \mathrm{wt} . \% \mathrm{Cr}, 7$ wt. $\% \mathrm{Fe}$ and $3 \mathrm{wt} . \% \mathrm{Al}$. When comparing both joints, a higher concentration of $\mathrm{Fe}$ and $\mathrm{Cr}$ was found for the sample joined at 1 hour than the sample joined at 30 minutes. The higher concentration of metals at the interface for the earlier sample led to the formation of the ductile layer, which enables it to absorb the residual stress during the cooling down process, consistent with Ibrahim et al.[32]. The obtained results showed that more $\mathrm{Cr}$ is diffused than Fe, which led to the formation of the intermetallic phase in the stainless steel interface.

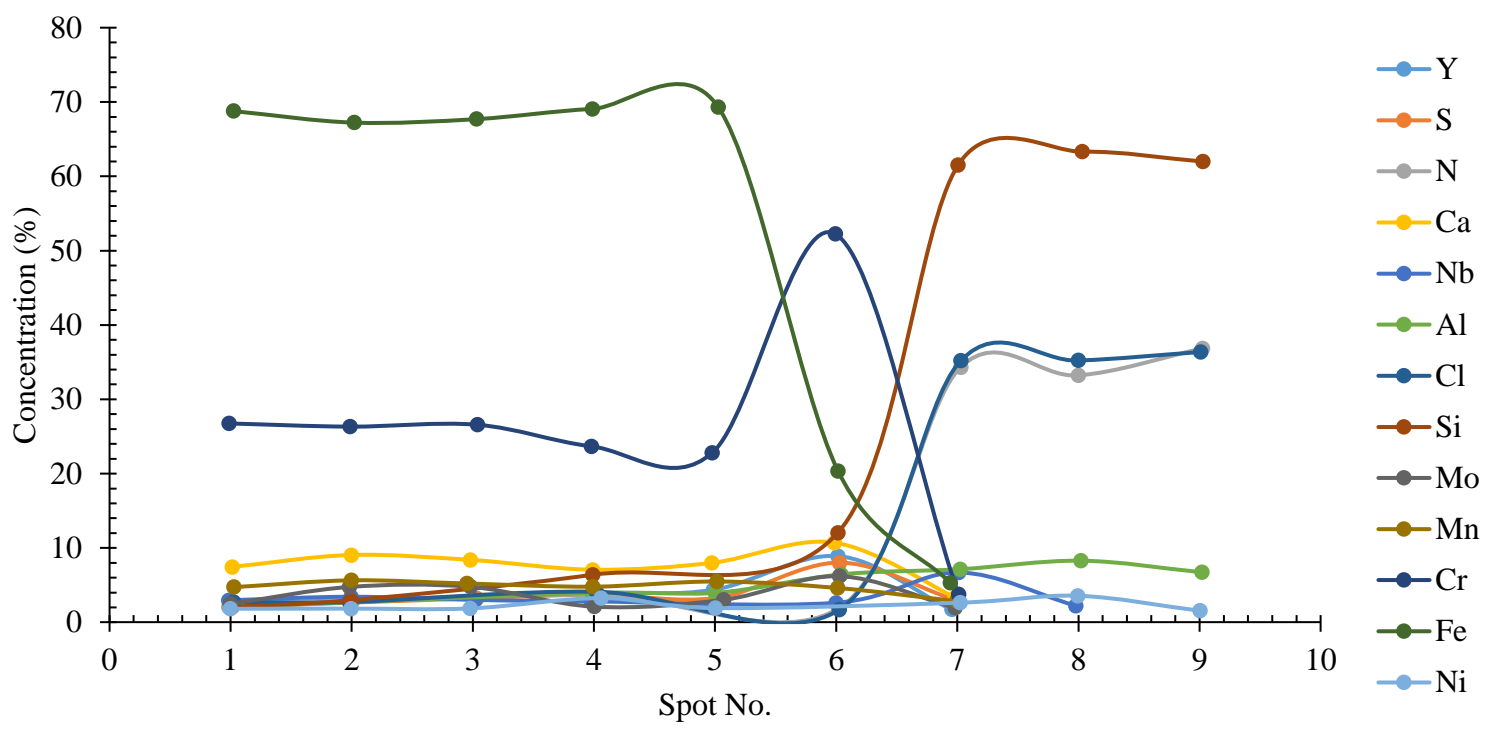

Figure 9. Elemental chart for 30 minutes sample

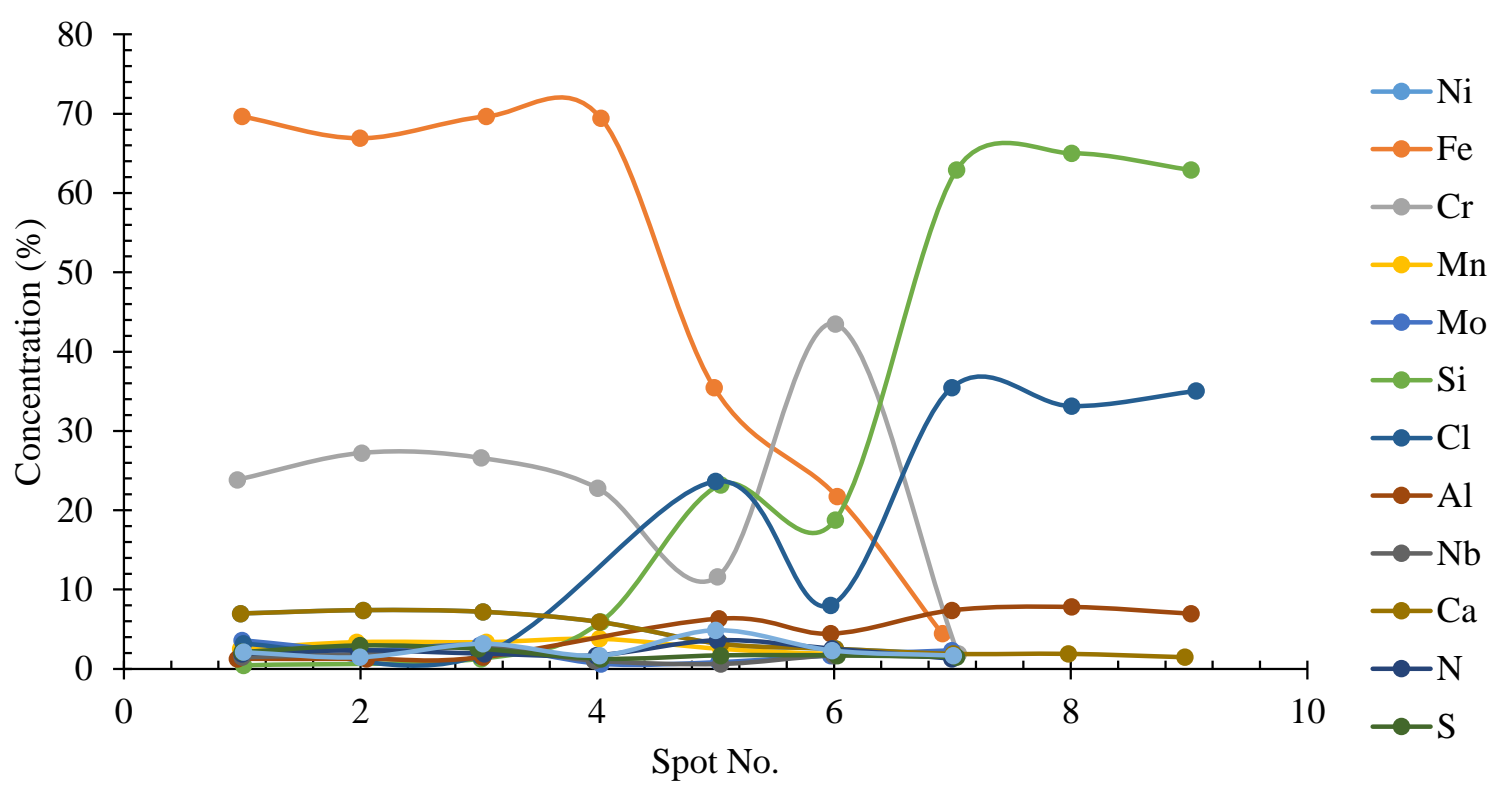

Figure 10. Elemental chart for 1-hour sample

For observation on 30 minutes sample, the highest Fe and $\mathrm{Cr}$ concentrations were found in spot 5 and reduced at spot 6, which corresponded to 68.17 and $50.31 \mathrm{wt} . \%$, respectively. In contrast, their least concentrations were 17.75 and 19.82 wt.\% in the respective spots of 6 and 5. In the 1-hour sample, Fe and Cr's highest concentrations were found in spot 1 and spot 6 , which corresponded to 68.27 and $42.53 \mathrm{wt}$. $\%$, respectively. In contrast, their minimum concentrations were 20.58 and $10.29 \mathrm{wt} . \%$ in the respective spots of 6 and 5 for the 1 -hour sample.

It can be interpreted that Fe's concentration was reduced when more $\mathrm{Cr}$ was present at that specific spot. It can also be observed that the concentration of Fe decreased where there was more $\mathrm{Cr}$ present at that particular spot. The concentrations of $\mathrm{Mn}$ and $\mathrm{Ni}$ from steel were not considered because their existence did not significantly impact the creation of a new phase at the joint. The phase transformations of both parent materials at the interface produced interface, and interdiffusion layers that enable the sound joined can be achieved. Research carried out on austenitic stainless steel to SiAlON [19] failed as the interface cannot accommodate residual stress. 


\section{CONCLUSIONS}

Thus, the diffusion bonding of dissimilar materials can produce transition layers or new phases consisting of the parent materials' constituents. The significant findings of this study are summarized as follows:

1) Joining for a 1-hour duration produced adequate interfacial bonding on both sides. However, joining for 30 minutes only produced satisfactorily results on one side.

2) Both samples' interfaces show the formation of diffusion layers consist of interdiffusion from both materials of duplex stainless steel and SiAlON.

3) The transformation of both materials' surfaces to interface and diffusion layers can accommodate the residual stress that arose during the joints' cooling process.

4) In the diffusion zone, chemical etching brings out the contact interface trace as a ferrite interlayer.

\section{ACKNOWLEDGMENTS}

The authors gratefully acknowledge the support provided by the Mechanical Engineering Department of Universiti Teknologi PETRONAS.

\section{REFERENCES}

[1] P. B. Hussain, "Diffusion bonding of sialon and stainless steel," Ph.D., University of Strathclyde, 1997. Accessed: Feb. 25, 2021. [Online]. Available: https://ethos.bl.uk/OrderDetails.do?uin=uk.bl.ethos.249842

[2] T. P. Nguyen et al., "Influence of SiAlON addition on the microstructure development of hot-pressed ZrB2-SiC composites," Ceramics International, vol. 46, no. 11, Part B, pp. 19209-19216, 2020, doi: 10.1016/j.ceramint.2020.04.258.

[3] C. Yin, J. Zhang, X. Li, P. Chen, and B. Zhu, "Simulation and experimental investigation of preferred $\beta$-Sialon growth and its effects on thermo-mechanical properties of Al2O3-C refractories," Ceramics International, vol. 45, no. 14, pp. 17298-17304, 2019, doi: 10.1016/j.ceramint.2019.05.288.

[4] H. Bian, Y. Song, D. Liu, Y. Lei, X. Song, and J. Cao, "Joining of SiO2 ceramic and TC4 alloy by nanoparticles modified brazing filler metal," Chinese Journal of Aeronautics, vol. 33, no. 1, pp. 383-390, 2020, doi: 10.1016/j.cja.2019.03.040.

[5] G. Wang et al., "Brazing ZrB2-SiC ceramics to Inconel 600 alloy without and with Cu foam," Journal of Manufacturing Processes, vol. 41, pp. 29-35, 2019, doi: 10.1016/j.jmapro.2019.03.023.

[6] N. Wang, D. P. Wang, Z. Yang, and Y. Wang, "Interfacial microstructure and mechanical properties of zirconia ceramic and niobium joints vacuum brazed with two Ag-based active filler metals," Ceramics International, vol. 42, no. 14, pp. 1281512824, 2016, doi: 10.1016/J.CERAMINT.2016.05.045.

[7] A. Abed, P. bin Hussain, I. S. Jalham, and A. Hendry, "Joining of sialon ceramics by a stainless steel interlayer," Journal of the European Ceramic Society, vol. 21, no. 16, pp. 2803-2809, 2001, doi: 10.1016/S0955-2219(01)00227-8.

[8] X. Ren, X. Chen, and Z. Xiong, "Characterization and analysis of diffusion bonding process in a Cr25Ni7Mo4MnSi duplex stainless steel," Journal of Manufacturing Processes, vol. 34, pp. 603-613, 2018, doi: 10.1016/j.jmapro.2018.07.005.

[9] S. Zeng, G. You, F. Yao, J. Luo, and X. Tong, "Effect of bonding temperature on the microstructure and mechanical properties of the diffusion-bonded joints of Zr705 alloy," Materials Science and Engineering: A, vol. 804, p. 140782, 2021, doi: 10.1016/j.msea.2021.140782.

[10] T. Lin et al., "An investigation on diffusion bonding of $\mathrm{Cu} / \mathrm{Cu}$ using various grain size of Ni interlayers at low temperature," Materialia, vol. 14, p. 100882, 2020, doi: 10.1016/j.mtla.2020.100882.

[11] C. Li et al., "Diffusion bonding of Ti and $\mathrm{Zr}$ at ultra-low temperature via surface nano-crystallization treatment," Materials Science and Engineering: A, vol. 785, p. 139413, 2020, doi: 10.1016/j.msea.2020.139413.

[12] S. D. Ji, Q. Wen, and Z. W. Li, “A novel friction stir diffusion bonding process using convex-vortex pin tools," Journal of Materials Science \& Technology, vol. 48, pp. 23-30, 2020, doi: 10.1016/j.jmst.2020.01.042.

[13] M. Elßner, S. Weis, T. Grund, G. Wagner, S. Habisch, and P. Mayr, "Microstructure of arc brazed and diffusion bonded joints of stainless steel and $\mathrm{SiC}$ reinforced aluminum matrix composite," IOP Conference Series: Materials Science and Engineering, vol. 118, p. 012037, 2016, doi: 10.1088/1757-899x/118/1/012037.

[14] C. Velmurugan, V. Senthilkumar, S. Sarala, and J. Arivarasan, "Low temperature diffusion bonding of Ti-6Al-4V and duplex stainless steel," Journal of Materials Processing Technology, vol. 234, pp. 272-279, 2016, doi: 10.1016/j.jmatprotec.2016.03.013.

[15] S. Kundu and S. Chatterjee, "Diffusion bonding between commercially pure titanium and micro-duplex stainless steel," Materials Science and Engineering: A, vol. 480, no. 1, pp. 316-322, 2008, doi: 10.1016/j.msea.2007.07.033.

[16] F. Hudiyo, P. Hussain, and O. Mamat, "Suppression of iron silicide formation in the reaction layer of Sialon $-7.5 \% \mathrm{Cr}$ ferritic steel joint," Defect and Diffusion Forum, 2011. https://www.scientific.net/DDF.312-315.888 (accessed Feb. 25, 2021).

[17] N. N. Md Ibrahim, P. Hussain, and M. Awang, "Diffusion bonding of Sialon to AISI 420 martensitic stainless steel with cut off heat upon cooling," Advanced Materials Research, 2016. https://www.scientific.net/AMR.1133.249 (accessed Feb. 25, 2021). 
[18] E. Akca and A. Gürsel, "The importance of interlayers in diffusion welding - A review," Periodicals of Engineering and Natural Sciences (PEN), vol. 3, no. 2, 2015, doi: 10.21533/pen.v3i2.54.

[19] P. Hussain and A. Isnin, "Joining of austenitic stainless steel and ferritic stainless steel to sialon," Journal of Materials Processing Technology, vol. 113, no. 1, pp. 222-227, 2001, doi: 10.1016/S0924-0136(01)00640-9.

[20] H. Firmanto, P. Hussain, and O. Mamat, "Reaction layers of the diffusion-bonded Sialon and high-chromium steel," Journal of Applied Sciences, 2011. http://eprints.utp.edu.my/7683/ (accessed Feb. 25, 2021).

[21] J. Qin, Q. Huang, X. Wang, X. Suo, J. Wang, and H. Li, "Interfacial metal/ceramic bonding mechanism for metallization of ceramics via cold spraying," Journal of Materials Processing Technology, vol. 288, p. 116845, 2021, doi: 10.1016/j.jmatprotec.2020.116845.

[22] X. Chen, J. Yan, S. Ren, Q. Wang, J. Wei, and G. Fan, "Microstructure, mechanical properties, and bonding mechanism of ultrasonic-assisted brazed joints of SiC ceramics with ZnAlMg filler metals in air," Ceramics International, vol. 40, no. 1, Part A, pp. 683-689, 2014, doi: 10.1016/j.ceramint.2013.06.055.

[23] Y. Zhang, D. Feng, Z. He, and X. Chen, "Progress in joining ceramics to metals," Journal of Iron and Steel Research, International, vol. 13, no. 2, pp. 1-5, 2006, doi: 10.1016/S1006-706X(06)60032-0.

[24] G. Kaur et al., "Mechanical properties of bioactive glasses, ceramics, glass-ceramics and composites: State-of-the-art review and future challenges," Materials Science and Engineering: C, vol. 104, p. 109895, 2019, doi: 10.1016/j.msec.2019.109895.

[25] M. Bock, I. Arrayago, E. Real, and E. Mirambell, "Study of web crippling in ferritic stainless steel cold formed sections," ThinWalled Structures, vol. 69, pp. 29-44, 2013, doi: 10.1016/j.tws.2013.03.015.

[26] A. M. Kliauga and M. Pohl, "Effect of plasma nitriding on wear and pitting corrosion resistance of X2 CrNiMoN 2253 duplex stainless steel," Surface and Coatings Technology, vol. 98, no. 1, pp. 1205-1210, 1998, doi: 10.1016/S0257-8972(97)002405 .

[27] B. Wang, S. Sun, M. Guo, G. Jin, Z. Zhou, and W. Fu, "Study on pressurized gas nitriding characteristics for steel 38CrMoAlA," Surface and Coatings Technology, vol. 279, pp. 60-64, 2015, doi: 10.1016/j.surfcoat.2015.08.035.

[28] B. Joshi, G. Gyawali, H. Wang, T. Sekino, and S. W. Lee, "Thermal and mechanical properties of hot pressed translucent Y2O3 doped $\mathrm{Mg}-\alpha / \beta-$ Sialon ceramics," Journal of Alloys and Compounds, vol. 557, pp. 112-119, 2013, doi: 10.1016/j.jallcom.2012.12.160.

[29] "Properties of SiAlON advanced ceramics for machining," AZoM.com, Dec. $17,2009$. https://www.azom.com/article.aspx?ArticleID=5065 (accessed Feb. 25, 2021).

[30] M. Hasan, J. Zhao, Z. Huang, L. Chang, H. Zhou, and Z. Jiang, "Analysis of sintering and bonding of ultrafine WC powder and stainless steel by hot compaction diffusion bonding," Fusion Engineering and Design, vol. 133, pp. 39-50, 2018, doi: 10.1016/j.fusengdes.2018.05.076.

[31] S. Kundu, M. Ghosh, A. Laik, K. Bhanumurthy, G. B. Kale, and S. Chatterjee, "Diffusion bonding of commercially pure titanium to 304 stainless steel using copper interlayer," Materials Science and Engineering: A, vol. 407, no. 1, pp. 154-160, 2005, doi: 10.1016/j.msea.2005.07.010.

[32] N. N. M. Ibrahim, P. Hussain, and M. Awang, "Microstructure and hardness of diffusion bonded Sialon-AISI 420 martensitic stainless steel," Advanced Materials Research, 2014. https://www.scientific.net/AMR.974.199 (accessed Feb. 25, 2021). 